\title{
Avaliação do conhecimento sobre urgências oftalmológicas dos acadêmicos da Faculdade de Medicina da Pontifícia Universidade Católica de Campinas
}

\author{
Assessment of knowledge about ophthalmic emergencies of \\ Pontifical Catholic University of Campinas medical students
}

Carolina Roman Rached ${ }^{1}$, Tiago Cena de Oliveira ${ }^{1}$, Camila Lacerda Muniz de Melo Sousa ${ }^{1}$, Isabela Minozzi Escudeiro', Lilian Pagano Mori ${ }^{1}$, Fernanda Proa Ferreira', Juliana Cixi Barbosa Xavier ${ }^{1}$, Beatriz Helena de Moraes Milioni', Renan Radaeli de Figueiredo', Mônica Alves de Paula²

\section{RESUMO}

Objetivo: Avaliar os conhecimentos sobre urgências oftalmológicas (UO) dos acadêmicos da Faculdade de Medicina da Pontifícia Universidade Católica de Campinas (PUC-Campinas). Métodos: Estudo transversal (inquérito) realizado entre os acadêmicos do primeiro ano e último ano da graduação. Foi aplicado um questionário padronizado contendo uma autoavaliação na qual os acadêmicos graduaram seu conhecimento em "bom", "regular" ou "insuficiente" e 10 questões de múltipla escolha abordando temas de UO. Os dados foram avaliados por medidas de tendência central e foram utilizados o Teste T de Student para a análise de variáveis contínuas e o Teste Qui-quadrado para variáveis categóricas através do software GraphPad InStat. Resultados: Foram entrevistados 70 acadêmicos do primeiro ano (77,7\% ) com média de idade igual a 20,9 anos e 49 acadêmicos do último ano (54,4\%) com média de idade igual a 24,9 anos. A maioria dos acadêmicos do primeiro ano $(83,1 \%)$ considerou seu conhecimento insuficiente e grande parte dos acadêmicos do último ano $(43,2 \%)$ considerou regular $(p=0,0001)$. A média das notas obtidas pelos acadêmicos de ambos os anos de graduação foi igual a 5,9, sendo 5,5 a média das notas do primeiro ano e 6,3 do último ano, com diferença estatisticamente significativa $(p=0,0065)$. Conclusão: Foram observadas deficiências no conhecimento sobre UO entre os acadêmicos no presente estudo. Os resultados obtidos serão utilizados pela Liga de Oftalmologia da PUC-Campinas como subsídios para traçar estratégias de ensino mais efetivas no curso de Oftalmologia da graduação.

Descritores: Avaliação; Conhecimentos, atitudes e prática em saúde; Estudantes de Medicina; Educação médica; Oftalmologia/educação; Emergências; Questionários

\footnotetext{
${ }^{1}$ Faculdade de Medicina da Pontifícia Universidade Católica de Campinas - PUC-Campinas - Campinas (SP), Brasil; ${ }^{2}$ Faculdade de Medicina da Pontifícia Universidade Católica de Campinas - PUC-Campinas - Campinas (SP), Brasil.

Trabalho realizado na Faculdade de Medicina da Pontifícia Universidade Católica de Campinas - PUC-Campinas - Campinas (SP), Brasil.
}

Os autores declaram inexistir conflitos de interesse

Recebido para publicação em 5/4/2011 - Aceito para publicação em 29/8/2011 


\begin{abstract}
Objective: To evaluate the knowledge base of Pontifical Catholic University of Campinas medical students regarding ophthalmic emergencies (OE). Methods: Cross-sectional survey among first-year and sixth-year medical students based on data collection obtained through a standardized questionnaire containing a self-evaluation test in which the students had to evaluate their knowledge into "good", "average" or "insufficient", and 10 multiple choice questions covering the OE themes. The data were evaluated using measures of central tendency and Student's $\mathrm{T}$ test for assessing the continous variables and the Chi-square test for the categorical variables using the GraphPad InStat software. Results: Seventy first-year medical students (77.7\%) with an average age of 20.9 years and 49 sixth-year medical students $(54.4 \%)$ with an average age of 24.9 years were interviewed. The majority of first-year medical students $(83.1 \%)$ considered their knowledge "insufficient" and, the majority of sixth-year medical students $(43.2 \%)$ classified their knowledge as "average" $(\mathrm{p}=0.0001)$. In the multiple choice questions, the first-year medical students obtained an average grade of 5.5 and the sixth-year medical students, 6.3 ( $\mathrm{p}=0.0065)$, thus the average grade obtained by both graduation levels was equal to 5.9. Conclusion: The study found deficiencies in knowledge about OE. The results of this study will be used by the Ophthalmology Study Group for planning effective strategies for better teaching ophthalmology.
\end{abstract}

Keywords: Evaluation; Health knowledge, attitudes, practice; Students, medical; Education, medical; Ophthalmology/education; Emergencies; Questionnaires

\section{$\underline{\text { INTRODUÇÃO }}$}

A s urgências oftalmológicas (UO) representam cerca de $7 \%$ dos atendimentos em prontos-so corros gerais $^{(1)}$. Dentre essas afecções oculares, as mais frequentes são: trauma ocular contuso ou perfurante, infecções oculares e orbitárias, glaucoma agudo e as queimaduras químicas ${ }^{(1,2)}$.

O primeiro atendimento de uma urgência oftalmológica (UO) é realizado geralmente por médicos não oftalmologistas em prontos-socorros gerais. São esses profissionais os primeiros a conduzirem os casos de UO e decidirem sobre o diagnóstico e tratamento iniciais $^{(3)}$. Deste modo, conhecimentos básicos em UO são necessários para se tomar uma conduta correta e precoce, evitando danos oculares severos e o comprometimento irreversível da acuidade visual.

Os médicos não oftalmologistas, em sua maioria, não se sentem seguros no atendimento de $\mathrm{UO}^{(3)}$. A insegurança no atendimento é o reflexo da formação insuficiente no ensino da Oftalmologia durante a graduação médica, o que pode levar ao retardo na condução adequada das UO e, consequentemente, ao risco potencial de dano ocular e diminuição da acuidade visual ${ }^{(4)}$. Desta forma, é imprescindível que a graduação ofereça condições adequadas para formar médicos capacitados a diagnosticar, tratar e encaminhar corretamente ao especialista os casos de urgências oftalmológicas atendidos em serviços não especializados ${ }^{(5,6)}$. Além dos conhecimentos em UO, o ensino da Oftalmologia deve também enfatizar a importância do diagnóstico de doenças sistêmicas com manifestações oculares presentes na ro- tina de diversas especialidades médicas e de doenças oculares de resolução simples ${ }^{(7)}$.

Deste modo, alterações curriculares e programas extracurriculares com o objetivo de aumentar o envolvimento do acadêmico com a especialidade durante a graduação, permitiriam consolidar o conhecimento em tópicos gerais e no atendimento de urgência. $\mathrm{O}$ melhor entendimento da Oftalmologia durante a graduação garante a formação de profissionais capacitados ao atendimento adequado, contribuindo para a saúde ocular e a prevenção da cegueira ${ }^{(6)}$.

Este estudo tem por objetivo avaliar e analisar os conhecimentos sobre urgências oftalmológicas entre os acadêmicos do primeiro ano e último ano de graduação da Faculdade de Medicina da PUC-Campinas, fornecendo subsídios para traçar estratégias curriculares de ensino e elaboração de atividades complementares a serem realizadas pela Liga de Oftalmologia da PUC-Campinas.

\section{Métodos}

Estudo de delineamento transversal (inquérito) realizado entre 119 acadêmicos (70 do primeiro ano e 49 do último ano) da Faculdade de Medicina da Pontifícia Universidade Católica de Campinas durante o período de agosto a setembro de 2010. As entrevistas foram realizadas pelos membros da Liga de Oftalmologia em dias específicos, que buscaram aleatoriamente os acadêmicos do primeiro e último ano de graduação que consentiram em participar do estudo.

O questionário elaborado para este estudo (Anexo 1 - Questionário) compilou dados pessoais referentes 
Tabela 1

Características individuais dos acadêmicos entrevistados

\begin{tabular}{llccc}
\hline & \multicolumn{2}{c}{ Primeiro ano } & \multicolumn{2}{c}{ Último ano } \\
\hline Características & $\mathbf{n}$ & $\%$ & $\mathbf{n}$ & $\%$ \\
Sexo & & & & \\
Masculino & 23 & 32,9 & 23 & 46,9 \\
Feminino & 47 & 67,1 & 26 & 53,1 \\
Mediana da idade & 20 & & 24 & \\
\hline
\end{tabular}

Tabela 2

Percentual das respostas em cada tema da autoavaliação e suas médias

\begin{tabular}{lcccccc}
\hline & \multicolumn{3}{c}{ Primeiro ano } & \multicolumn{3}{c}{ Último ano } \\
\hline Temas & Bom & Regular & Insuficiente & Bom & Regular & Insuficiente \\
Queimaduras químicas & 2,9 & 10 & 87,1 & 36,7 & 32,7 & 30,6 \\
Trauma ocular & 1,4 & 12,9 & 85,7 & 36,7 & 44,9 & 18,4 \\
Perfurações oculares & 1,4 & 11,4 & 87,1 & 34,7 & 44,9 & 20,4 \\
Fratura de órbitas & 2,9 & 5,7 & 91,4 & 10,2 & 38,8 & 51 \\
Glaucoma agudo & 1,4 & 21,4 & 77,1 & 18,4 & 42,9 & 38,8 \\
Infecções oculares & 5,7 & 24,3 & 70 & 22,4 & 55,1 & 22,4 \\
Médias & 2,6 & 14,3 & 83,1 & 26,5 & 43,2 & 30,3 \\
\hline
\end{tabular}

ao acadêmico entrevistado (nome, sexo, idade e ano de graduação), uma autoavaliação do conhecimento de UO e 10 questões de múltipla escolha sobre o tema.

Na autoavaliação, os entrevistados julgaram o seu conhecimento em UO como "bom", "regular" ou "insuficiente" em cada um dos temas abordados (queimaduras químicas, trauma ocular, perfurações oculares, fraturas de órbita, glaucoma agudo e infecções oculares e orbitárias) e, nas questões de múltipla escolha, foram avaliados quanto à conduta escolhida em cada questão, recebendo uma nota (escala de 0 a 10) segundo o total de questões respondidas corretamente.

Foi estabelecido como "desempenho esperado"o índice de acerto nas questões de múltipla escolha maior que $80 \%$ ou nota maior ou igual a 8 , sendo a nota máxima igual a 10.

Os dados coletados foram tabulados no Microsoft Excel® e avaliados por medidas de tendência central. Também foram utilizados o Teste $\mathrm{T}$ de Student para a análise de variáveis contínuas e Teste Qui-quadrado para variáveis categóricas através do software GraphPad Instat ${ }^{\circledR}$ versão 3.05. O nível de significância adotado foi de $p<0,05$.

Todos os entrevistados que participaram da pesquisa consentiram em publicar os resultados deste estudo resguardando as suas identidades.

\section{$\underline{\text { RESULTADOS }}$}

Foram entrevistados 70 acadêmicos do primeiro ano $(77,7 \%)$ com idades entre 18 e 34 anos (mediana de 20 anos) e 49 acadêmicos do último ano de graduação com idades entre 22 e 47 anos (mediana de 24 anos), totalizando 119 acadêmicos entrevistados (Tabela 1). Observa-se que a maioria dos acadêmicos era do sexo feminino em ambos os anos de graduação $(67,1 \%$ dos acadêmicos do primeiro ano e $53,1 \%$ dos acadêmicos do último ano).

Com relação à autoavaliação, a maioria dos acadêmicos do primeiro ano $(83,1 \%)$ considerou seu conhecimento em UO "insuficiente", como apresentado na Tabela 2. Por outro lado, a maior parte dos acadêmicos do último ano (43,2\%) julgou seu conhecimento em UO "regular". Destacou-se, também, o aumento nos percentuais da resposta "bom" em todos os temas julgados pelos acadêmicos do último ano em relação aos do primeiro ano.

Apenas no tema sobre queimaduras químicas que a maioria $(36,7 \%)$ dos acadêmicos do último ano respondeu "bom". Porém, grande parte $(51 \%)$ dos acadêmicos do último ano julgou "insuficiente" o seu conhecimento em fratura de órbita. 
Para a análise da autoavaliação foram considerados os conceitos "Bom" e "Ruim", sendo este a somatória das cotações de "Regular" e "Insuficiente". Assim, os acadêmicos do último ano tiveram uma associação significativa com a autoavaliação ruim $(p=0,0001)$.

Os acadêmicos do último ano obtiveram maiores índices de acerto nas questões de múltipla escolha que os acadêmicos do primeiro ano (Figura 1).

A maior parte dos acadêmicos do primeiro ano $(87,1 \%)$ tomou uma conduta correta na questão referente à conjuntivite bacteriana. Em contrapartida, o maior índice de acerto $(93,9 \%)$ entre os acadêmicos do último ano foi observado nas questões sobre queimadura química e conjuntivite bacteriana.

O pior desempenho obtido por ambos os anos de graduação foi observado na questão referente a corpo estranho, apresentando percentual de acerto de $7,1 \%$ e $12,2 \%$ entre os acadêmicos do primeiro ano e último ano, respectivamente.

A média das notas do último ano foi igual a 6,3, não tão superior à média do primeiro ano: 5,5 , sendo a mediana das notas do último ano igual a 6 (nota mínima: 3 , nota máxima: 10) e do primeiro ano igual a 5,5 (nota mínima: 2, nota máxima: 8). Houve diferença estatisticamente significativa entre as notas obtidas de cada ano de graduação $(p=0,0065)$. Considerando ambos os desempenhos de cada ano, os 119 acadêmicos entrevistados obtiveram nota média igual a 5,9 nas questões de múltipla escolha.

O melhor desempenho (nota máxima) observado entre os acadêmicos do primeiro ano foi com a nota 8 , sendo a menor nota (nota mínima) igual a 2 (Figura 2). Por outro lado, no último ano, houve quem atingisse a nota máxima 10, sendo a menor nota observada igual a 3.

A maioria dos acadêmicos de cada ano (moda) obteve nota $6,27,1 \%$ dos acadêmicos do primeiro ano e $22,4 \%$ dos acadêmicos do último ano (Figura 2).

\section{Discussão}

Em estudo recente ${ }^{(3)}, 93 \%$ dos médicos plantonistas não oftalmologistas se sentem inseguros no atendimento de casos de UO e, como consequência, há a ineficácia em realizar o diagnóstico precoce e encaminhar o paciente adequadamente ao especialista, o que pode levar ao desenvolvimento de complicações e pior prognóstico visual, principalmente se não houver uma intervenção precoce ${ }^{(5)}$. Corroborando com esse dado, foi observado neste estudo, através da análise dos dados da autoavaliação, que a maioria dos acadêmicos do último ano de graduação $(73,5 \%)$ avaliou seu conhecimento em UO como "regular" ou "insuficiente", refletindo a

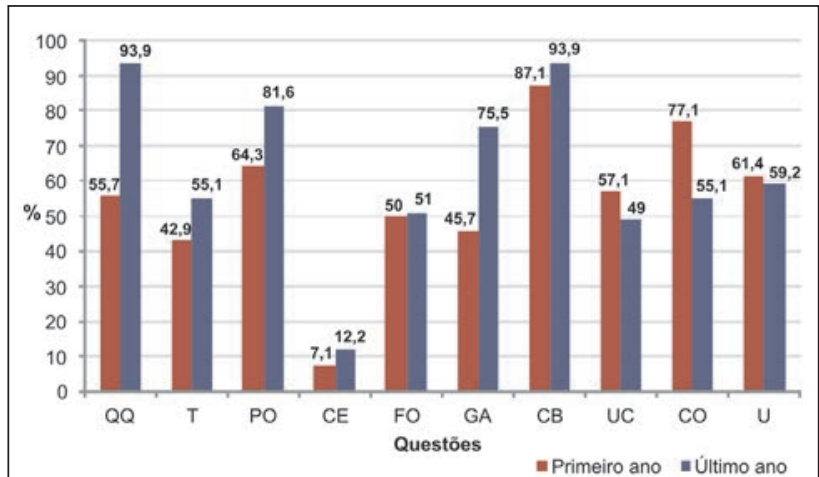

QQ: queimadura química; T: trauma; PO: perfuração ocular; CE: corpo estranho; FO: fratura de órbita; GA: glaucoma agudo. CB: conjuntivite bacteriana; UC: úlcera de córnea; CO: celulite orbitária; U: uveíte.

Figura 1: Percentual de acerto em cada questão obtido pelos acadêmicos

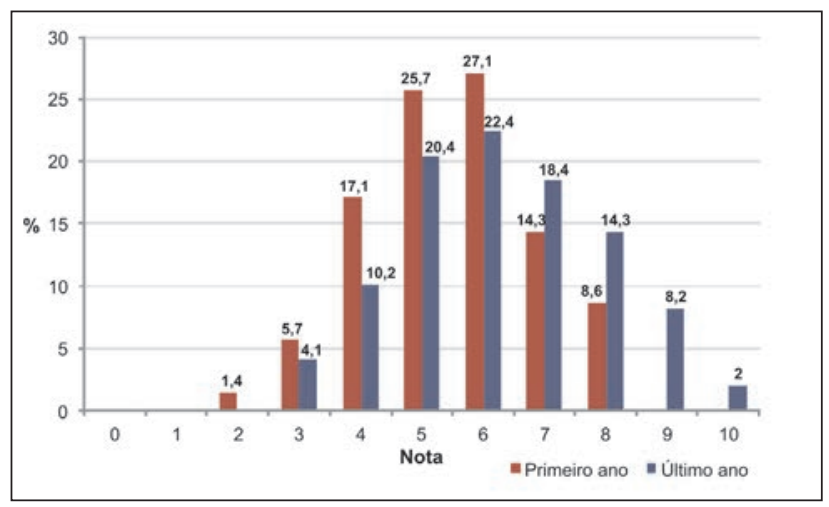

Figura 2: Percentual da frequência das notas obtidas pelos acadêmicos

insegurança de plantonistas responsáveis pelo atendimento inicial de casos de UO.

A deficiência de conhecimentos básicos em Oftalmologia observada entre os acadêmicos de graduação é apontada como um dos principais fatores que contribui para a insegurança no atendimento de $\mathrm{UO}^{(3,4)}$. $\mathrm{E}$ está também, consequentemente, relacionada a condutas incorretas que, por vezes, são prejudiciais ao paciente, principalmente se praticadas por médicos não especialistas $^{(4)}$. Este cenário é temeroso, pois já foi evidenciado em estudo realizado anteriormente ${ }^{(4)}$ que os acadêmicos do último ano de graduação obtiveram baixos índices de acerto em questões abordando os temas de UO.

No presente estudo, verificou-se que apenas 14,3\% dos acadêmicos do último ano tiveram desempenho superior ao esperado ${ }^{(4)}$ (nota maior ou igual a 8 ) e, de modo semelhante, apenas $8,6 \%$ dos acadêmicos do primeiro se destacaram nas questões de múltipla escolha. Estes baixos percentuais sugerem que poucos acadêmicos possuem um nível de conhecimento sobre UO adequado.

Levando em consideração o desempenho obtido 


\section{Anexo 1}

\section{Questionário}

Prezado graduando,agradecemos pela sua colaboração com este estudo intitulado "Avaliação do conhecimento sobre urgências oftalmológicas dos acadêmicos da Faculdade de Medicina da Pontifícia Universidade Católica de Campinas", que tem por finalidade avaliar o conhecimento sobre urgências oftalmológicas entre os acadêmicos do primeiro ano e último ano da Faculdade de Medicina da Pontifícia Universidade Católica de Campinas, permitindo o aprimoramento do ensino em Oftalmologia. Com a sua participação neste estudo, você autoriza a publicação dos resultados deste trabalho sem comprometer a sua identidade.

Identificação:Nome:

Sexo:

Idade: Ano:

Parte 1 - Auto-avaliação:Como você avalia seus conhecimentos nas seguintes situações de urgências oftalmológicas:

1. Queimaduras químicas:

2. Trauma ocular:

3. Perfurações oculares:

4. Fraturas de órbita:

5. Glaucoma agudo:

6. Infecções oculares e/ou orbitárias:

$\begin{array}{ll}\text { () bom } & (\text { ) regular } \\ \text { () bom } & \text { () regular } \\ \text { bom } & \text { () regular } \\ \text { () bom } & \text { () regular } \\ \text { () bom } & \text { () regular } \\ \text { () bom } & \text { () regular }\end{array}$

) insuficiente

( ) insuficiente

( insuficiente

( ) insuficiente

( ) insuficiente

( ) insuficiente

Parte 2 - Questões:

1.Na suspeita de queimadura química. Qual seria, em sua opinião, a conduta correta?

( ) Encaminhar o paciente imediatamente ao oftalmologista.

( ) Utilizar colírios com antibióticos e analgésicos.

( ) Lavagem exaustiva do olho com solução fisiológica.

( ) Curativo oclusivo não compressivo e encaminhar ao oftalmologista.

2. Na suspeita de trauma contuso com descolamento de retina. Qual seria, em sua opinião, a conduta correta?

( ) Encaminhar o paciente imediatamente ao oftalmologista.

( ) Utilizar colírios com antibióticos e analgésicos.

( ) Lavagem exaustiva do olho com solução fisiológica.

( ) Curativo oclusivo não compressivo e encaminhar ao oftalmologista.

3. Na suspeita de perfuração ocular após traumatismo. Qual seria, em sua opinião, a conduta correta?

( ) Encaminhar o paciente imediatamente ao oftalmologista.

( ) Utilizar colírios com antibióticos e analgésicos.

( ) Lavagem exaustiva do olho com solução fisiológica.

( ) Curativo oclusivo não compressivo e encaminhar ao oftalmologista.

4. Na suspeita de corpo estranho ocular. Qual seria, em sua opinião, a conduta correta?

( ) Encaminhar o paciente imediatamente ao oftalmologista.

( ) Utilizar colírios com antibióticos e analgésicos.

( ) Lavagem exaustiva do olho com solução fisiológica e remoção do corpo estranho.

( ) Curativo oclusivo não compressivo e encaminhar ao oftalmologista.

5. Na suspeita de fratura de órbita. Qual seria a sua conduta?

( ) Encaminhar o paciente imediatamente ao oftalmologista.

( ) Utilizar colírios com antibióticos e analgésicos e radiografia de órbitas.

( ) Lavagem exaustiva do olho com solução fisiológica.

( ) Curativo oclusivo não compressivo e encaminhar ao oftalmologista.
6. Na suspeita de glaucoma agudo. Qual seria a sua conduta?

( ) Encaminhar o paciente imediatamente ao oftalmologista.

( ) Utilizar colírios com antibióticos e analgésicos.

( ) Administração de hipotensores e sintomáticos.

( ) Curativo oclusivo não compressivo e encaminhar ao oftalmologista.

7. Na suspeita de conjuntivite bacteriana. Qual seria a sua conduta?

( ) Encaminhar o paciente imediatamente ao oftalmologista.

( ) Utilizar colírios com antibióticos e orientações de higiene.

( ) Lavagem exaustiva do olho com solução fisiológica.

( ) Curativo oclusivo não compressivo e encaminhar ao oftalmologista.

8. Na suspeita de úlcera de córnea. Em sua opinião, qual seria a conduta correta?

( ) Encaminhar o paciente imediatamente ao oftalmologista.

( ) Utilizar colírios com antibióticos e analgésicos.

( ) Lavagem exaustiva do olho com solução fisiológica.

( ) Curativo oclusivo não compressivo e encaminhar ao oftalmologista.

9. Na suspeita de celulite orbitária. Em sua opinião, qual seria a conduta correta?

( ) Encaminhar o paciente imediatamente ao oftalmologista.

( ) Utilizar colírios com antibióticos e analgésicos.

( ) Lavagem exaustiva do olho com solução fisiológica.

( ) Curativo oclusivo não compressivo e encaminhar ao oftalmologista.

10. Na suspeita de uveíte. Em sua opinião, qual seria a conduta correta?

( ) Encaminhar o paciente imediatamente ao oftalmologista.

( ) Utilizar colírios com antibióticos e analgésicos.

( ) Lavagem exaustiva do olho com solução fisiológica.

( ) Curativo oclusivo não compressivo e encaminhar ao oftalmologista. 
nas questões de múltipla escolha, os acadêmicos do último ano obtiveram percentual de acerto maior que $80 \%$ em apenas três questões (queimadura química, perfuração ocular e conjuntivite bacteriana), e, em menor proporção, os acadêmicos do primeiro ano tiveram desempenho semelhante apenas na questão sobre conjuntivite bacteriana. Deste modo, houve um melhor desempenho nas questões de fácil compreensão e resolução, demonstrando um nível de conhecimento relativamente superficial sobre UO.

Analisando as médias das notas dos acadêmicos de ambos os anos de graduação, houve um desempenho discretamente superior dos acadêmicos do último ano $(6,3)$ em relação aos do primeiro ano $(5,5)$, com pouca diferença (igual a 0,8 ) entre essas médias, o que reflete o pouco conhecimento em UO adquirido pelos acadêmicos durante a graduação. Essa diferença entre as médias é explicada pela maior frequência de notas altas (maiores que 8) presentes somente entre os acadêmicos do último ano, mesmo que a nota 6 seja a mais frequente tanto no último quanto no primeiro ano de graduação. Assim, a diferença entre as notas de cada ano estudado foi estatisticamente significativa $(p=0,0065)$.

Em estudo realizado em 6 escolas médicas, foram avaliados os conhecimentos em Oftalmologia entre os acadêmicos do último ano de graduação, sendo observado que, em nenhuma das questões aplicadas, os acadêmicos obtiveram índice de acerto maior que $80 \%{ }^{(4)}$. Entretanto, os acadêmicos, avaliados no presente estudo, obtiveram um melhor desempenho em relação aos acadêmicos do estudo anterior, como já demonstrado pelo maior número de questões com índice de acerto maior que $80 \%$.

Os dados obtidos neste estudo apontam para a necessidade de melhorias consideráveis e eficientes no ensino da Oftalmologia. Para tanto, deve-se enfatizar a necessidade de maior atenção e valorização desta disciplina na graduação médica, especialmente quando se refere a condições que representam risco para a visão como as UO.

O ensino da Oftalmologia na graduação deve fornecer condições adequadas para a formação de futuros médicos capazes de prevenir, identificar e conduzir de forma adequada situações clínicas do dia a dia com envolvimento ocular ${ }^{(4)}$. Da mesma forma, atividades extracurriculares podem ser desenvolvidas com o intuito de complementar o ensino da Oftalmologia( ${ }^{(7)}$.

Os dados obtidos neste estudo serão fundamentais para um melhor planejamento de estratégias de ensino mais efetivas e propiciar atividades extracurriculares complementares elaboradas pela Liga de Oftalmologia da PUC-Campinas, abordando principalmente temas sobre UO. As propostas sugeridas pela
Liga incluem: realização de cursos de UO, discussão de tópicos de oftalmologia relacionados a outras especialidades médicas, como clínica médica, pediatria, reumatologia e endocrinologia, atividades supervisionadas de ambulatório e pronto-socorro, elaboração de projetos com ação comunitária e realização de simpósios. Essas atividades poderão contribuir para a vivência do acadêmico na especialidade, demonstrando a importância de conhecimentos básicos em Oftalmologia no manejo de pacientes com afecções oculares e, principalmente, no atendimento adequado de pacientes com UO em prontos-socorros gerais.

Este estudo permitiu avaliar o conhecimento em urgências oftalmológicas dos acadêmicos de graduação da Faculdade de Medicina da PUC-Campinas constituindo parte das atividades realizadas pelos membros da Liga de Oftalmologia da PUC-Campinas. Deste modo, mesmo com uma diferença significativa entre o número de acadêmicos participantes de cada ano e com uma amostragem pequena, foi possível utilizar os resultados obtidos para avaliar simplificadamente o conhecimento em UO dos acadêmicos.

\section{ReFERÊNCIAS}

1. Layaun SEED, Schor P, Rodrigues MLV. Perfil da demanda de um serviço de oftalmologia em uma unidade de emergência. Rev Bras Oftalmol. 1992;51(3):171-3.

2. Weyll M, Silveira RC, Fonseca Júnior NL. Trauma ocular aberto: características de casos atendidos no Complexo Hospitalar Padre Bento de Guarulhos. Arq Bras Oftalmol. 2005;68(4):505-10.

3. Espíndola RF, Teixeira FC, Yamakami IM, Silva HRF, Freitas JAH. Análise dos conhecimentos básicos sobre urgências oftalmológicas em plantonistas não-oftalmologistas. Arq Bras Oftalmol. 2006;69(1):11-5.

4. Ginguerra MA, Ungaro ABS, Villela FF, Kara-José AC, KaraJosé N. Aspectos do ensino de graduação em oftalmologia. Arq Bras Oftalmol. 1998;61(5):546-50.

5. May DR, Kuhn FP, Mornis RE, Witherspoon CD, Danis RP, Matthews GP, Mann L. The epidemiology of serious eye injuries from the United States Eye Injury Registry. Graefes Arch Clin Exp Ophthalmol. 2000;238(2):153-7.

6. Silva MRBM. O Ensino da Oftalmologia. Rev Bras Oftalmol. 2009;68(3):127-8.

7. Kara-José AC, Passos LB, Kara-José FC, Kara-José N. Ensino extracurricular em Oftalmologia: grupos de estudos / ligas de alunos de graduação. Rev Bras Educ Méd. 2007;31(2):166-72.

\section{Endereço para correspondência: \\ Monica Alves de Paula \\ Rua da Urca, $n^{\circ} 550$ \\ CEP 13104-184 - Campinas - SP}

E-mail: monicalves1@uol.com.br 